\title{
Influence of Grinding Procedures on the Flexural Strength of Zirconia Ceramics
}

\author{
Ufuk İSERI ${ }^{1}$ \\ Zeynep ÖZKURT ${ }^{1}$ \\ Ender KAZAZOĞLU ${ }^{1}$ \\ Davut KÜÇÜKOĞLU² \\ ${ }^{1}$ Yeditepe University Faculty of Dentistry, Department of Prosthodontics, Istanbul, Turkey \\ ${ }^{2}$ Private Practice, Istanbul, Turkey
}

\begin{abstract}
The surface of zirconia may be damaged during grinding, influencing the mechanical properties of the material. The purpose of this study was to compare the flexural strength of zirconia after different grinding procedures. Twenty bar-type zirconia specimens $(21 \mathrm{x}$ $5 \times 2 \mathrm{~mm}$ ) were divided into 4 groups and ground using a high-speed handpiece or a low-speed straight handpiece until the bars were reduced $1 \mathrm{~mm}$ using two different grinding times: continuous grinding and short-time grinding $(\mathrm{n}=5)$. Control specimens $(\mathrm{n}=5)$ were analyzed without grinding. The flexural strengths of the bars were determined by using 3-point bending test in a universal testing machine at a crosshead speed of $0.5 \mathrm{~mm} / \mathrm{min}$. The fracture load $(\mathrm{N})$ was recorded, and the data were analyzed statistically by the Kruskal Wallis test at a significance level of 0.05 . In the test groups, high-speed handpiece grinding for a short time had produced the highest mean flexural strength $(878.5 \pm 194.8 \mathrm{MPa})$, while micromotor continuous grinding produced the lowest mean flexural strength $(733.8 \pm 94.2 \mathrm{MPa})$. The control group was the strongest group $(928.4 \pm 186.5 \mathrm{MPa})$. However, there was no statistically significant differences among the groups $(\mathrm{p}>0.05)$. Within the limitations of the study, there was no difference in flexural strength of zirconia specimens ground with different procedures.
\end{abstract}

Key Words: zirconia, grinding, flexural strength.

\section{INTRODUCTION}

Zirconia based ceramics are gaining popularity especially in fixed prosthodontics because of their superior mechanical properties and the development of new fabrication technologies for the all-ceramic crowns and fixed partial dentures (1). Zirconia $\left(\mathrm{ZrO}_{2}\right)$ is a polymorphic material that has 3 allotropes. The monoclinic phase is stable up to $1170^{\circ} \mathrm{C}$ and it transforms into the tetragonal phase which is stable up to $2370^{\circ} \mathrm{C}$. The cubic phase is stable up to $2680^{\circ} \mathrm{C}$, which is also the melting point (2). Mechanical properties rely on this tetragonal-monoclinic transformation, which is martensitic in nature (3). This transformation can be induced by externally applied stress and is associated with a relatively large volume expansion (3 to 5\%), which results in the development of internal stresses opposing a crack and, therefore, acts to increase the resistance of the material to crack propagation (4).
Furthermore, grinding and airborne-particle abrasion, with the ability to transform zirconia on the surface, can introduce residual compressive stresses that increase the flexural strength of zirconia based ceramics (5). Severe grinding can introduce deep surface flaws that act as stress concentrators and can reduce strength values (6).

In the manufacturing technology of zirconia ceramic post systems, implant abutments, orthodontic brackets and fixed partial denture frameworks, shaping and sintering of zirconia with subsequent machining to adjust a final form are involved (7). Hence, tetragonal zirconia ceramic will be transformed to monoclinic zirconia and damaged. This transformation would affect the mechanical properties and reliability of zirconia (8).

In a fixed partial restoration, the stability, marginal fit and occlusion of the framework should be verified. In many cases, adjustments by grinding may be required to improve the fitting of the restoration which returned from

Correspondence: Dr. Zeynep Özkurt, Yeditepe University, Faculty of Dentistry Department of Prosthodontics, Bağdat cad. No: 238, 34728 Goztepe, Istanbul, Turkey. Tel: 00-9021-6363-6044. Fax: 00-9021-6363-6211. e-mail: zeynepozkurt@hotmail.com 
the laboratory for a trial fitting before applying veneer ceramic (1). These changes are performed to provide sufficient interocclusal distance, proximal contacts or to achieve acceptable marginal fit between material and tooth. Similar requirements are valid for zirconia implant abutments. They may be required small changes especially for interocclusal distance.

On the other hand, before cementation of a zirconia post, it should be reshaped to achieve accurate fit between the post and root canal. Also, the root surface of the post should be prepared to increase adhesion to luting agents (9). These adjustments may be carried out by grinding with rotary instruments in the clinic or in the laboratory. Grinding of zirconia may affect the mechanical properties of restorations. Whereas the effects of machining and grinding of zirconia on flexural strength is examined and well known, comparison of high-speed, air-driven dental handpiece grinding with diamond burs or low-speed straight handpiece grinding with silicon carbide abrasives has not been examined. The aims of this study were to evaluate the effect of grinding on the flexural strength of yttrium stabilized tetragonal zirconia and to compare the effect of grinding procedures with two different timing strategy: continuous grinding and short-time grinding. The research hypothesis was that the flexural strength of zirconia could be different with any kinds of grinding procedures.

\section{MATERIAL AND METHODS}

\section{Specimen Fabrication}

Yttrium oxide stabilized zirconium oxide bars were cut from presintered zirconia blocks (Zirkonzahn, Steger, Italy). The specimens were cut oversized because approximately $25 \%$ shrinkage occurs during sintering to full density. Then, zirconia bars were sintered to full density according to the manufacturer's instructions until they reached final dimensions ( $21 \mathrm{~mm}$ long, $5 \mathrm{~mm}$ wide and $2 \mathrm{~mm}$ high). The bars were polished under watercooling by using a grinder-polisher machine (Phoenix Beta Grinder/Polisher, Buehler, Germany). The purpose of this standardized polishing procedure was to remove external irregular scratches and to round the chipped corners of the specimens symmetrically.

\section{Grinding Procedures}

Test specimens consisted of 20 zirconia bars. Half of the specimens $(n=10)$ were ground with a high-speed handpiece (625DN Super Torque; KaVo, Biberach, Germany) and the other half ( $\mathrm{n}=10)$ were ground with a low-speed straight handpiece (EX-203, NSK, Japan). The specimens were prepared with diamond burs (Axis Dental Corp., Zir-cut, Z878K-021, Coppell, TX, USA) for high-speed handpiece with the rotational speed of 320,000 rpm, and with silicon carbide abrasives (Hager\&Meisinger; Z732 Medium, Neuss, Germany) for low-speed straight handpiece with the rotational speed of 22,000 rpm. The silicon carbide abrasives were $5.1 \mathrm{~mm}$ in diameter and $12.5 \mathrm{~mm}$ in length, and they had straight cylindrical geometry. The diamond burs were $2.1 \mathrm{~mm}$ in diameter, $8 \mathrm{~mm}$ in length and they had straight cylindrical geometry with chamfer edge. A new bur was used for each zirconia surface. Five bars of each were randomly assigned to each of 4 test groups. Zirconia bars were marked $1 \mathrm{~mm}$ away from the length with permanent pen, and were ground until $1 \mathrm{~mm}$ reduction was achieved with continuous grinding, and $5 \mathrm{~s}$ grinding. Control specimens were analyzed without grinding $(\mathrm{n}=5)$.

\section{Grinding Apparatus}

A custom-made grinding apparatus was designed to mount both the specimens and the grinding devices (Fig. 1). The high-speed handpiece and the low-speed straight handpiece were clamped to a straight holding arm which could move up and down. A metal fragment with two screws, which carried the specimens, was also attached to the apparatus. The low-speed straight handpiece were adjusted to be above the metal fragment, producing contact of the bars with the rotating grinding burs. A constant load of $100 \mathrm{~g}$, which is typically employed by clinicians in finishing procedures, was used

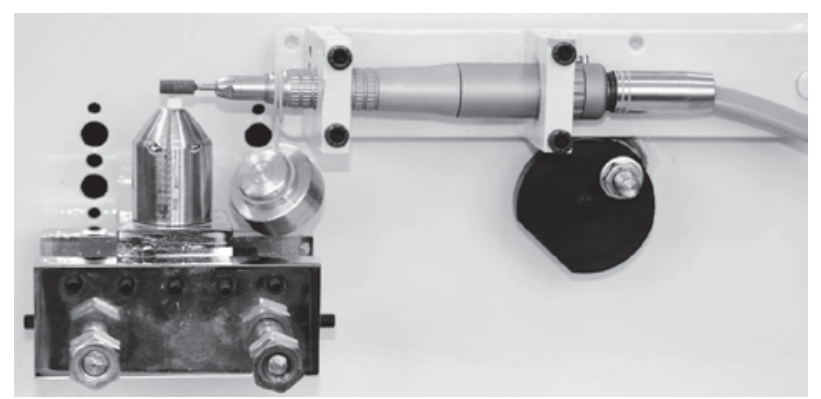

Figure 1. Grinding apparatus. 
by applying free weight on the holding arm in the cutting experiments (10). The burs were oriented approximately parallel to the $5 \times 21 \mathrm{~mm}$ surface and they were positioned in contact with the specimens. The direction of applied force produced a horizontal cut on the bar until $1 \mathrm{~mm}$ reduction was achieved. The grinding devices were run with 2 different timing procedures. In the first group, continuous grinding was applied. In the second group, the devices were run for $5 \mathrm{~s}$ with the cutting duration of $5 \mathrm{~s}$. The burs were removed from the grinding devices prior to the other specimens. Then, specimens were removed from the apparatus, ultrasonically cleaned in water for $30 \mathrm{~s}$ before the 3-point bending test.

\section{Flexural Strength Test}

The flexural strengths of the zirconia bars were determined by using a 3-point bending test, performed in a universal testing machine (Model 3345; Instron, Canton, MA, USA) at a crosshead speed of $0.5 \mathrm{~mm} /$ $\min$. The bars were prepared to ensure that the top and bottom surfaces were put parallel to produce uniform contact with the two 5-mm-diameter rollers. This uniform contact was verified visually.

The ultimate load that caused specimen fracture was recorded in Newton (N). Mean fracture strengths (MPa) were calculated using the following equation as recommended by the ISO 6872 standard (11): Fracture strength $(\mathrm{MPa})=3 \mathrm{WL} / 2 \mathrm{bd}^{2}$, where, W: fracture load $(\mathrm{N})$, L: length of specimen ( $\mathrm{mm}), \mathrm{b}$ : width of specimen $(\mathrm{mm}), \mathrm{d}$ : thickness of specimen $(\mathrm{mm})$.

Kruskal-Wallis test was used to assess whether there was any statistical difference among groups at a

Table 1. Mean biaxial flexural strength values, standard deviations (SD) and medians in $\mathrm{MPa}(\mathrm{n}=5)$, and results of Kruskal Wallis test.

\begin{tabular}{lcc}
\hline Groups & Mean (SD) & Median \\
\hline Control & $928.40(186.55)$ & 912.58 \\
HS + CG & $878.57(194.85)$ & 820.95 \\
HS + STG & $823.53(92.08)$ & 798.71 \\
LS + CG & $838.91(151.22)$ & 826.70 \\
LS + STG & $733.82(94.22)$ & 771.33 \\
Kruskal Wallis & 3.486 & \\
Significance & 0.480 & \\
HS = high-speed handpiece; LS = low-speed straight handpiece; \\
CG = continuous grinding; STG = short-time grinding.
\end{tabular}

significance level of 0.05 .

\section{RESULTS}

Three-point bending flexural strength mean values and standard deviations were presented in Table 1. There was no statistically significant difference $(\mathrm{p}>0.05)$ among the groups (Table 1).

Based on the flexural strength data, the nonground control group was the strongest group (928.4 \pm 186.5 MPa). In the high-speed handpiece group, zirconia specimens showed the mean flexural strength of 878.5 $\pm 194.8 \mathrm{MPa}$ after $5 \mathrm{~s}$ grinding with duration, and 823.5 $\pm 92.1 \mathrm{MPa}$ after continuous grinding. In the low-speed straight handpiece group, the specimens showed the mean flexural strength of $838.9 \pm 151.2 \mathrm{MPa}$ after 5 $\mathrm{s}$ grinding with duration, and $733.8 \pm 94.2 \mathrm{MPa}$ after continuous grinding. Comparing the test groups, highspeed handpiece grinding for $5 \mathrm{~s}$ produced the highest (878.5 $\pm 194.8 \mathrm{MPa})$, and low-speed straight handpiece continuous grinding protocol produced the lowest values $(733.8 \pm 94.2 \mathrm{MPa})$ (Table 1).

Although there was no significant differences, zirconia specimens that were ground continuously with low-speed straight handpiece had 14\% lower flexural strength than short-time grinding. However, this percentage was $6 \%$ for high-speed handpiece. The zirconia specimens in control group had $26 \%$ higher flexural strength than continuous grinding with lowspeed straight handpiece, $12 \%$ higher flexural strength than continuous grinding with high-speed handpiece, $10 \%$ higher flexural strength than short time grinding with low-speed straight handpiece and 5\% higher flexural strength than short-time grinding with highspeed handpiece groups.

\section{DISCUSSION}

In this study, the effect of low-speed straight handpiece and high-speed handpiece grinding on biaxial flexural strength of zirconia was compared. The influence of grinding time (continuous and short-time grinding) was also evaluated. Grinding procedures used in the study simulated to clinical and laboratory conditions. Based on the obtained results, the tested hypothesis was accepted. It was shown that all grinding procedures had a counteracting effect on the flexural strength of zirconia, but this decrease was not statistically significant.

The low-speed straight handpiece grinding 
continuously, which was believed to produce higher temperature, resulted in the lowest flexural strength values ( $26 \%$ decrease). The minimum drop in flexural strength was obtained in high-speed grinding with duration (5\%). Therefore, lower temperature might be produced during this grinding procedure.

Grinding may introduce residual surface compressive stresses that can increase the strength of zirconia ceramics considerably $(5,6)$. On the other hand, severe grinding may introduce deep surface flaws, which act as stress concentrators if their length largely exceeds the depth of the grinding induced surface compressive layer (12). In the present study, zirconia specimens that were ground continuously had lower flexural strength compared to short-time grinding, for both low-speed straight handpiece (14\%) and high-speed handpiece $(6 \%)$ groups.

Swain and Hannink (13) stated that hand grinding is more effective than machine grinding in inducing the $\mathrm{t} \rightarrow \mathrm{m}$ transformation and therefore, increasing the mean flexural strength of the ceramic. They demonstrated that in the case of machine grinding, the local development of temperatures exceeded the $\mathrm{m} \rightarrow \mathrm{t}$ transformation temperature, causing the reverse $\mathrm{m} \rightarrow \mathrm{t}$ transformation. In this instance, the deep defects introduced by grinding are no longer counteracted by the transformation-induced compressive stresses and act as stress concentrators, lowering the mean flexural strength of the ceramic (13).

Kosmac et al. (8) investigated the influence of sandblasting, wet and dry grinding that was carried out by hand with a $150 \mu \mathrm{m}$ grit size diamond bur mounted on a high-speed. They showed that the relative content of monoclinic phase and the flexural strength of ground specimens were less than sandblasted zirconia specimens. When they ground the samples with a coarse grit size diamond bur mounted on a high-speed handpiece used at 150,000 rpm, they stated that sparks were seen during the procedure. An explanation for the lower strength and lower content of monoclinic phase was given by assuming that grinding had caused local development of temperatures that must have exceeded the temperature to which the reverse $\mathrm{m} \rightarrow \mathrm{t}$ phase transformation occurs. The flexural strength of zirconia specimens were $724 \mathrm{MPa}$ in dry ground and coarse bur group and $914 \mathrm{MPa}$ in control group (8). The rotational speed used in the present study $(320,000 \mathrm{rpm})$ were different from that used by Kosmac et al. (8), and this speed might developed lower temperatures, explaining why the flexural strength of the ground specimens did not drop so much (928.4 MPa in the control group and 823.5-878.5 MPa in the high-speed handpiece group) in this study.

Xu et al. (14) reported an improvement in strength of zirconia upon fine grinding with $25 \mathrm{~mm}$ grit size diamond burs, whereas coarser grinding resulted in strength reduction. Papanagiotou et al. (15) stated that the temperature increase during the polishing procedure (polishing with $10 \mu \mathrm{m}$ and $30 \mu \mathrm{m}$ girt size with 6,500 rpm low-speed straight handpiece) was not high enough to cause any reverse transformation, resulting in higher flexural strength (827.9 MPa in the control group and 844.3 MPa in the polishing group). In the present study, coarser grinding procedures were performed at low- $(220$ $\mu \mathrm{m})$ and high-speed $(150 \mu \mathrm{m})$. The flexural strength values were reduced between 5-26\%, when compared to non-ground control group.

In operative dentistry, pulpal response to highspeed rotation is considerably less traumatic than to low-speed rotation. High-speed rotary instruments produce less force and heat compared to lower-speed procedures (16). In implant surgery, it was reported that high-speed drilling produced the least heat, decreasing the risk of bone damage, which might affect the initial healing of dental implants $(17,18)$. In the present study, zirconia specimens ground with high-speed handpiece at 320,000 rpm showed higher mean flexural strength (8\%) than low-speed straight handpiece at 22,000 rpm. This ratio was attributed to the least heat generation during grinding procedure with high-speed instrument.

The results of the analysis of zirconia specimens showed that the flexural strengths were variable, ranging from 733.8 to $928.4 \mathrm{MPa}$. Nevertheless, even the lowest flexural strength value recorded (733.8 MPa) was more than $500 \mathrm{MPa}$, a value that exceeds the occlusal loads commonly recorded intraorally, with the exception of patients possessing clenching and bruxing habits $(19,20)$.

In conclusion, all grinding procedures had a counteracting effect on the flexural strength of zirconia (5-26\% decrease), but this decrease was not statistically significant. However, if adjustments are required to improve the fitting of the zirconia based restorations, grinding with high-speed devices in the clinic may help preventing mechanical damage of zirconia ceramics. Furthermore, time of grinding, continuous or with short duration, may also influence the flexural strength. Future studies are needed with larger sample size, measuring the heat generation during grinding with different instruments, burs and timing. 


\section{RESUMO}

A superfície da zircônia pode ser danificada durante o desgaste, influenciando as propriedades mecânicas do material. O objetivo deste estudo foi comparar a resistência à flexão da zircônia após diferentes procedimentos de desgaste. Vinte amostras de zircônia em formato de barra $(21 \times 5 \times 2 \mathrm{~mm})$ foram divididos em 4 grupos e desgastados usando uma peça de mão de alta velocidade e um micromotor até as barras terem sido reduzidas $1 \mathrm{~mm}$ usando dois tempos diferentes de desgaste: desgaste contínuo e desgaste de curta duração $(n=5)$. Amostras de controle (sem desgaste; $\mathrm{n}=5$ ) foram analisadas. A resistência à flexão das barras foi determinada utilizando o ensaio de flexäo em três pontos numa máquina universal de ensaios a uma velocidade cruzeta de 0,5 $\mathrm{mm} / \mathrm{min}$. A carga de fratura $(\mathrm{N})$ foi registrada, e os dados foram analisados estatisticamente com o teste Kruskal-Wallis com o nível de significância de 0,05 . Não houve diferenças estatisticamente significantes entre os grupos ( $\mathrm{p}>0,05)$. Nos grupos teste, o desgaste de curta duração usando peça de mão de alta velocidade foi o mais alto $(878,5 \pm 194,8 \mathrm{MPa})$, e o desgaste contínuo com o micromotor apresentou o valor mais baixo $(733,8 \pm 94,2 \mathrm{MPa})$. O grupo controle foi o mais forte $(928,4 \pm 186,5 \mathrm{MPa})$. Dentro das limitações do estudo, não houve diferença na resistência à flexão das amostras da zircônia desgastadas com procedimentos diferentes.

\section{REFERENCES}

1. Qeblawi DM, Muñoz CA, Brewer JD, Monaco EA Jr. The effect of zirconia surface treatment on flexural strength and shear bond strength to a resin cement. J Prosthet Dent 2010;103:210-220.

2. Subbarao EC. Zirconia-an overview. Adv Ceram 1981;3:1-24.

3. Garvie RC, Hannink RH, Pascoe RT. Ceramic steel? Nature 1975;258:703-704.

4. Luthardt RG, Holzhuter M, Sandkuhl O, et al. Reliability and properties of ground Y-TZP-Zirconia ceramics. J Dent Res 2002;81:487-491.

5. Gupta TK. Strengthening by surface damage in metastable tetragonal zirconia. J Am Ceram Soc 1980;63:117-121.

6. Green DJ. A technique for introducing surface compression into zirconia ceramics. J Am Ceram Soc 1983;66:178-179.
7. Meyenberg KH, Luthy H, Scharer P. Zirconia posts: a new all-ceramic concept for nonvital abutment teeth. J Esthet Dent 1995;7:73-80.

8. Kosmac T, Oblak C, Jevnikar P, Funduk N, Marion L. The effect of surface grinding and sandblasting on flexural strength and reliability of Y-TZP zirconia ceramic. Dental Materials 1999;15:426-433.

9. Oblak C, Jevnikar P, Kosmac T, Funduk N, Marion L. Fracture resistance and reliability of new zirconia posts. J Prosthet Dent 2004;91:342-348.

10. Siegel SC, Von Fraunhofer JA. Dental cutting with diamond burs: heavyhanded or light touch? J Prosthodont 1999;8:3-9.

11. International Organization for Standardization. ISO 6872:1995 (E): Dental ceramics.

12. Luthardt RG, Holzhuter MS, Rudolph H, Herold V, Walter MH. CAD/CAM-machining effects on Y-TZP zirconia. Dent Mater 2004;20:655-662.

13. Swain MV, Hannink RHJ. Metastability of the martensitic transformation in a $12 \mathrm{~mol} \%$ ceria-zirconia alloy: grinding studies. J Am Ceram Soc 1989; 72:1358-1364.

14. $\mathrm{Xu} \mathrm{HKK}$, Jahanmir S, Ives LK. Effect of grinding on strength of tetragonal zirconia and zirconia-toughened alumina. Machining Science and Technology 1997;1:49-66.

15. Papanagiotou HP, Morgano SM, Giordano RA, Pober R. In vitro evaluation of low-temperature aging effects and finishing procedures on the flexural strength and structural stability of Y-TZP dental ceramics. J Prosthet Dent 2006;96:154-164.

16. Cohen S, Hargreaves KM. Pathways of the pulp. 9th ed. St. Louis: Mosby Inc.; 2006, p523.

17. Sharawy M, Misch CE, Weller N, Tehemar S. Heat generation during implant drilling: the significance of motor speed. J Oral Maxillofac Surg 2002;60:1160-1169.

18. Iyer S, Weiss C, Mehta A. Effects of drill speed on heat production and the rate and quality of bone formation in dental implant osteotomies. Part II: Relationship between drill speed and healing. Int J Prosthodont 1997;10:536-540.

19. Suarez MJ, Lozano JFL, Paz Salido MP, Martinez F. Three-year clinical evaluation of In-Ceram Zirconia posterior FPDs. Int J Prosthodont 2004; 17:35-38.

20. Kern M, Knode H, Strubb JR. The all-porcelain, resin-bonded bridge. Quintessence Int 1991;22:257-262.

Accepted June 11, 2010 